\title{
Resenha: El mágico número tres: Cuando los niños aún no hablan
}

\author{
Cecilia Guarnieri Batista ${ }^{1}$ \\ Maria Eduarda Silva Leme \\ Universidade Estadual de Campinas
}

Como abordar o início do conhecimento em bebês que ainda não falam? Esse foi o desafio que Rodríguez e Moro se propuseram a enfrentar, remetendo, primeiro, a Piaget, autor com quem concordam no que se refere à concepção de que o conhecimento é construído. Apresentam, a seguir, suas discordâncias, criticando a ênfase desse autor na interação exclusiva com o objeto, e sua concepção de um sujeito solipsista, que vai construindo solitária e isoladamente o conhecimento.

Contrapõem a essa concepção as idéias de Vygotsky, dando especial destaque à noção de mediação semiótica. Consideram, entretanto, que essa noção tem sido reduzida à de mediação lingüística, o que deixa de fora meios menos elaborados de mediação semiótica. É a busca da compreensão destes outros processos semióticos que orienta seu estudo, voltado para bebês que ainda não falam, e que já apresentam várias formas de interação com o adulto, bem como de manuseio de objetos.

Ao mesmo tempo, as autoras criticam concepções dualistas de desenvolvimento, que contrapõem mundo físico a mundo social, pensamento a comunicação, aspectos cognitivos (internos) a aspectos sociais (externos). Realizam extensa revisão crítica da literatura recente, em que diferentes autores acabam centrando-se em um ou outro pólo dessas dicotomias.

Preconizam que uma epistemologia antidualista necessita uma pragmática do objeto. Deve levar em conta que os objetos têm usos, e estes são fruto de convenção social. Os objetos assumem significados socialmente compartilhados, construídos na interação social, passando, assim, a ser signos de seu uso. Trata-se, portanto, de uma concepção de objeto muito diferente da adotada correntemente em estudos psicogenéticos.

As autoras colocam, assim, a necessidade de enfocar, ao mesmo tempo, a interação social e a pragmática do objeto, constituindo, como foco de análise, o triângulo criança adulto - objeto, abordados de forma unitária, sem a fragmentação freqüentemente observada nos estudos da criança em seus primeiros anos de vida.

\footnotetext{
${ }^{1}$ Endereço para correspondência: Av. N S Fátima, 805, Acapulco, 111, 13090902 , Campinas, SP. Fone/Fax: (19) 32514677.E-mail:cecigb@fcm.unicamp.br
}

Uma vez que se trata de bebês que ainda não falam, as autoras consideram necessário ampliar o conceito de mediação lingüística para o de mediação semiótica. Sustentam que essa foi a proposta original de Vygostky, reduzida, segundo elas, ao de mediação lingǘstica, em muitos estudos. Para tanto, recorrem a Peirce ${ }^{2}$, cuja concepção de signo é bastante abrangente, tendo a linguagem como o mais elaborado dos signos, com suas características de arbitrariedade e convencionalidade, mas também levando em conta outras formas de significação. As autoras consideram que o sistema de Peirce permite detectar os primórdios do uso de signos, desde os mais icônicos e próximos ao "objeto", mas já trazendo o início da semiose, até os mais arbitrários. Isso é propiciado pelas noções de primeiridade, segundidade e terceiridade, e seus correspondentes ícone, índice e símbolo, que representam graus progressivos de aquisição na direção da arbitrariedade e convencionalidade. Além disso, elas propõem a adaptação da teoria de Peirce à psicogênese, propondo uma seqüência de aquisição, principiando na primeiridade e progredindo até a terceiridade. Utilizam-se também da concepção de Peirce de que o signo é inferência e não tradução, e lançam mão do conceito de inferência abdutiva para compreender o processo pelo qual a criança vai progressivamente se aproximando do uso convencional dos objetos. A partir da interação com o adulto e tendo por base regras - no início muito rudimentares e gradualmente tornando-se mais gerais e convencionais -, a criança formula "hipóteses" (abduções) sobre o que fazer com os objetos e que uso dar a eles.

Em seguida, as autoras apresentam o estudo empírico, que envolveu a observação de seis díades mãe-bebê, em três faixas etárias: 7 meses, 10 meses, 13 meses, em um corte longitudinal. Foi observada a interação da mãe com o bebê em suas casas. Eram oferecidos dois objetos, um de cada vez, por um período de cinco minutos. Um dos objetos era um telefone de brinquedo, na forma convencional (com fone e dial), com rodinhas, tendo, em sua face anterior, o desenho de um rosto sorridente. O outro objeto era um caminhão, também de plástico, com a carroceria em forma de baú basculante que, em sua parte superior, possuía seis aberturas em diversos formatos, nas quais podiam ser

${ }^{2}$ Textos sobre a teoria de Peirce: Nöth (1995), Peirce (1974) e Santaella (2001). 
encaixadas peças nas formas correspondentes. Na parte frontal da cabine estava desenhado um rosto sorridente.

Todas as sessões foram filmadas e transcritas com detalhes. As categorias de observação eram as seguintes: atenção, emoção, uso não canônico do objeto, utilização preliminar $^{3}$ ao uso canônico do objeto, uso canônico (ou convencional) do objeto e mediadores comunicativos desses usos. Entre os usos canônicos para o caminhão incluíam-se "colocar peças sobre a área de encaixe", "fazer movimentos (corretos e incorretos) até o encaixe" e "colocar peças pela porta traseira". Para o telefone, incluíam-se "girar o dial" e "telefonar" (com o fone junto à orelha, mesmo que em posições diferentes da convencional). Como exemplo de utilização preliminar ao uso canônico, incluíam-se, para o caminhão, "bater com a peça sobre a plataforma de encaixe" e "colocar o dedo num dos orifícios para encaixe" e, para o telefone, "tirar o fone do gancho" e "trazer o fone para perto de si". Entre as categorias de mediadores comunicativos, incluíam-se "mostrar o objeto, segurando-o na mão ${ }^{4}$ ", "apontar partes específicas do objeto (Ex.: um orifício específico de encaixe)" e "fazer demonstrações de uso".

$\mathrm{Na}$ definição dessas categorias, foram apresentadas modalidades das mesmas, indicando variações de circunstâncias e objetos envolvidos. As autoras não as consideraram como um sistema fechado de subcategorias. Ao invés disso, realizaram uma análise quantitativa compreendendo contagem de freqüências das categorias mais abrangentes e uma análise qualitativa dessas variações e modulações. Essa análise baseou-se em relatos de episódios "completos", com descrição de ações e reprodução de falas e, também, em relatos de ocorrências mais pontuais de variações das categorias centrais. Um exemplo se refere à categoria relativa a uso canônico de objeto "falar ao telefone", da qual foram destacadas as seguintes variações: "com fio ao contrário", "com fone no ombro" e "com fone no ouvido".

Os resultados mostraram que, aos 7 meses, os bebês utilizavam os objetos de modo indiferenciado, não canônico. Do ponto de vista semiótico, isso foi explicado como atribuição de significados icônicos: o vínculo que une o representamen ao objeto imediato é de natureza icônica. O bebê realiza com o objeto aquilo que este fisicamente lhe permite (sacudir, puxar, chupar, etc), com usos situados na esfera da primeiridade. Nos raros casos de preliminares ao uso canônico, e mais raros ainda de uso canônico, estes eram resultado de esforços e intervenções diretas do adulto. Por sua vez, as práticas mais freqüentes dos adultos consistiam em mostrar e demonstrar usos de objetos,

\footnotetext{
${ }^{3}$ Premisas no original.

${ }^{4}$ Ostensiones no original.
}

segurando-os e não indicando-os ${ }^{5}$. Em termos da teoria de Peirce, consideram que aos 7 meses o objeto ainda não é signo de seu uso convencional.

Ao mesmo tempo, as autoras sugerem que as ações do adulto sobre o objeto têm o efeito de destacar aspectos desse objeto, demonstrar uma seleção de usos possíveis, enfim, promover recortes que dirigem a atenção da criança e contribuem para a passagem da primeiridade para a segundidade. A significação do objeto sobre o qual o adulto age vai passando a ser indicial para a criança, o que implica uma maior proximidade com o uso convencional. Assim, os mediadores comunicativos do adulto começam a produzir uma progressão em direção a processos semióticos mais elaborados, aproximando a criança dos usos convencionais do objeto.

Os resultados relativos à faixa etária de 10 meses mostraram que os bebês utilizavam os objetos de três formas - usos não canônicos, preliminares e canônicos -, de forma flutuante. Nessa idade, os bebês começaram a utilizar os objetos de modo canônico e a tomar iniciativas. Pela teoria de Peirce, considera-se que o objeto começa a ser signo de seu uso: converte-se em representamen que mantém um vínculo de tipo convencional com seu objeto imediato. As autoras comentam que esse uso canônico muitas vezes surgia depois que o adulto o havia sugerido, com gestos de apontar amplificados por redundâncias. Ao mesmo tempo, com crianças dessa idade, os adultos realizavam menos gestos de mostrar e demonstrar, com o objeto na mão, e mais gestos de apontar, de indicar direção.

Aos 13 meses, as autoras observaram um aumento na freqüência dos usos canônicos e das exigências dos adultos (Ex.: apontar uma abertura específica de encaixe, e a criança trazer o objeto até este encaixe). Observaram, também, maior redução do mostrar e demonstrar em relação ao período anterior, e aumento na freqüência dos gestos de apontar. Constataram, ainda, diferenças nas formas de comunicação, na presença de um e de outro objeto. Comentaram que só se pode explicar a homogeneidade de muitas atuações da criança em relação aos objetos, se considerarmos que elas possuem regras em virtude das quais representamen e objeto imediato mantêm uma relação convencional.

$\mathrm{O}$ estudo indicou que as crianças se apropriam gradualmente dos usos convencionais dos objetos. $\mathrm{O}$ adulto apresenta esses usos, e vai alterando as modalidades de comunicação à medida que o bebê vai passando a apresentar mais usos convencionais, e o objeto se torna signo de seu uso. O objeto adquire conotação cultural na interação criança - objeto - adulto (este como representante da cultura). As

${ }^{5}$ No original, utilizando ostensiones e não gestos de señalar. 
autoras argumentam que, se não fosse assim, os usos convencionais estariam presentes aos 7 meses.

Consideramos que o livro traz várias contribuições interessantes, tais como a integração teórica entre a concepção de mediação por signos de Vygotksy e a semiótica de Peirce, que permitiu captar o início dos processos semióticos em bebês que ainda não falam.

Além disso, as autoras conseguem uma abordagem não dualista, em que as relações entre "criança que ainda não fala", "objeto com significado cultural" e "adulto mediador" são concebidas formando um triângulo, como unidade indivisível para a compreensão do início da construção do conhecimento. A concepção do objeto segundo uma perspectiva pragmática resgata sua dimensão social, relegada a segundo plano em grande parte dos estudos sobre o desenvolvimento.

O modo de realizar a análise de dados trouxe a combinação de modalidades quantitativas e qualitativas de análise. A quantificação foi centrada nas categorias amplas, e envolveu o cômputo de freqüências simples ou de dados percentuais das mesmas, trazendo um panorama geral da distribuição dessas categorias nas diferentes faixas etárias. Ao mesmo tempo, as modulações e variações foram apresentadas de modo qualitativo, a partir de uma retomada constante dos protocolos de transcrição, com destaque de elementos significativos para os objetivos do estudo. Isso pode ser exemplificado pela análise dos usos do telefone. A análise quantitativa indicou um aumento da freqüência da categoria abrangente "usos canônicos". Por outro lado, sem quantificação das subcategorias possíveis, foram descritas mudanças na forma que esses usos assumiam. Dessa forma, foi apontado o aumento do "falar ao telefone com o fone no ouvido na posição convencional", e a redução do "falar ao telefone com o fio ao contrário" ou "com o fone no ombro".
Uma crítica que poderia ser feita refere-se à escolha dos objetos, particularmente do caminhão. De fato, o que se selecionou como uso canônico foram as atividades de encaixe, e não a de rodar o caminhão. Nesse caso, talvez tivesse sido mais interessante a escolha de uma caixa de encaixes, e não de um caminhão para a realização do estudo. $\mathrm{Na}$ mesma direção, o telefone tinha rodas, o que também não nos parece a melhor escolha, já que o uso convencional selecionado referiu-se à simulação do telefonema.

O livro traz, dessa forma, significativa contribuição teórica e metodológica ao estudo do desenvolvimento humano. Aborda a questão da aquisição do uso convencional dos objetos a partir da interação entre o bebê que ainda não fala e sua mãe, como adulto mediador e representante da cultura em que estão imersos. Propõe uma adaptação dos conceitos da semiótica de Peirce para sua utilização em uma perspectiva psicogenética. Possibilita melhor compreensão das formas iniciais de mediação por signos que já estão presentes antes da linguagem, preenchendo uma lacuna nas formulações de Vygotsky sobre a gênese da mediação semiótica no ser humano. Inova, assim, na abordagem às relações entre mãe - bebê - objeto em seu uso convencional, uma trilogia que as autoras denominam como o "mágico número três".

\section{Referências}

Nöth, W. (1995). Panorama da semiótica: De Platão a Peirce. São Paulo: Annablume. Peirce, C. S. (1974). Escritos coligidos (Coleção Os Pensadores, Vol. 36) (A. M. D’Oliveira, Seleção) (A. M. D’Oliveira \& S. Pomerangblum, Trads.). São Paulo: Abril.

Rodriguez, C. \& Moro, C. (1999). El mágico numero três: Cuando los niños aún non hablan. Barcelona: Paidós.

Santaella, L. (2001). O que é semiótica São Paulo: Brasiliense.

Recebido: 12/03/2003

$1^{a}$ Revisão: $14 / 05 / 2003$

Aceite Final: 21/05/2003

Sobre as autoras

Cecilia Guarnieri Batista é Psicóloga, Mestre e Doutora pelo Instituto de Psicologia da Universidade de São Paulo. É Docente do Cepre, Faculdade de Ciências Médicas da Universidade Estadual de Campinas, onde ministra aulas nos cursos de Fonoaudiologia e Especialização em deficiência visual e surdez e faz pesquisa sobre desenvolvimento de crianças com deficiências.

Maria Eduarda Silva Leme é Psicóloga, Mestre pela Faculdade de Educação da Universidade Estadual de Campinas. É Coordenadora técnica do Centro Cultural Louis Braille de Campinas. É Psicóloga de reabilitação profissional do Institituto Nacional de Seguridade Social. É Psicóloga Clínica. 


\section{MESTRADO E DOUTORADO EM PSICOLOGIA DO DESENVOLVIMENTO}

2004

Se você é graduado em Psicologia, tem um bom domínio da língua inglesa e deseja se preparar para ser um pesquisador, professor universitário, ou mesmo um profissional de alta qualificação, o Programa de Pós-Graduação em Psicologia do Desenvolvimento da Universidade Federal do Rio Grande do Sul é o local que você procura. Desfrute de um ambiente acadêmico estimulante, onde alunos e professores convivem diariamente, com dedicação integral ao estudo e à pesquisa. Escreva-nos pedindo maiores informações.

INFORMAÇÕES E INSCRIÇÃO

UFRGS

UNIVERSIDADE FEDERAL

DO RIO GRANDE DO SUL

Instituto de Psicologia

PROGRAMA DE PÓS-GRADUAÇÃO EM PSICOLOGIA DO DESENVOLVIMENTO

Secretaria do PPG em Psicologia do Desenvolvimento - UFRGS

Rua Ramiro Barcelos, 2600, térreo Campus da Saúde

90035003 Porto Alegre RS Brasil

Fone: (51) 33165246 Fax: (51) 33165473

http://www.psicologia.ufrgs.br

E-mail: ppgdesen@ufrgs.br 